\title{
Biofilm formation, antimicrobial susceptibility, serogroups and virulence genes of uropathogenic $E$. coli isolated from clinical samples in Iran
}

\author{
Elahe Tajbakhsh ${ }^{1 *}$, Parvin Ahmadi ${ }^{2}$, Elham Abedpour-Dehkordi ${ }^{2}$, Nazila Arbab-Soleimani ${ }^{3}$
}

and Faham Khamesipour ${ }^{4}$

\begin{abstract}
Background: Uropathogenic Escherichia coli O- Serogroups with their virulence factors are the most prevalent causes of UTIs. The present research performed to track common uropathogenic E.coli serogroups, antibiotic resistance pattern of strains and prevalence of virulence genes in isolations having the ability to constitute biofilm.

Methods: In this research 130 E.coli isolation from patients having UTI symptoms were collected and antimicrobial resistance pattern was performed by Kirby-Bauer method. Polymerase chain reaction was done using primer pairs to identify common serogroups of uropathogenic E.coli and studying virulence genes in isolations creating biofilm.

Results: Among 130 E.coli isolates, 80 (61.53\%) were able to make biofilm that 15 isolates (18.75 \%) indicated strong reaction, 20 (25\%) of medium and 45 (56.25\%) of weak biofilm reaction. Among isolations creating biofilm, the highest resistance reported to Ampicillin (87.5\%) and the lowest to Nitrofurantoin (3.75\%). The frequency of fimH, pap, sfa and afa genes in isolations having the ability to create strong biofilm reported $93.33 \%, 86.66 \%, 86.66 \%$ and $66.66 \%$, respectively.

Conclusions: The findings indicated the importance of virulence genes in serogroups producing uropathogenic E.coli biofilm. It is recommended that strains producing biofilm before antibiotic use should be studied.
\end{abstract}

Keywords: Antibiotic resistance pattern, Biofilm, Virulence genes, Uropathogenic E. coli, Urinary Tract Infection

\section{Background}

Urinary tract infections (UTI) are common causes of morbidity and sometimes lead to significant mortality. Escherichia coli (E. coli) was the most common etiological agent of UTI, accounting for nearly $80 \%$ of community-acquired and $50 \%$ of hospital-acquired infections [1] and tends to form microcolonies in mucosa lining of urinary bladder known as biofilm. These biofilms make the organism to resist the host immune

\footnotetext{
* Correspondence: ee_tajbakhsh@yahoo.com

'Department of Microbiology, Faculty of Basic Sciences, Shahrekord Branch, Islamic Azad University, Shahrekord, Iran

Full list of author information is available at the end of the article
}

response, more virulent and lead to the evolution of antibacterial drug resistance by enclosing them in an extracellular biochemical matrix [2]. Biofilms have a role in up to $60 \%$ of human infections and they are very difficult to be eradicated with antimicrobial therapy. In vitro susceptibility tests have shown considerable increase in resistance of biofilm cells to killing [3]. Detection of biofilm-producer strains is therefore relevant for the design of adequate control measures for Uropathogenic E. coli (UPEC) infections.

The Escherichia coli strains are normally identified by serological typing of their $\mathrm{H}$ (flagellar), $\mathrm{O}$ (lipopolysaccharide) and in some cases, $\mathrm{K}$ (capsular) surface antigens. 
Overall, 184 O-serogroups are described for E. coli [4]. The O-serogroups of UPEC strains are related to certain virulence factor profile of each strain. Previous studies reported that $\mathrm{O} 1, \mathrm{O} 2, \mathrm{O} 4, \mathrm{O} 6, \mathrm{O} 7, \mathrm{O} 8, \mathrm{O} 15, \mathrm{O} 16, \mathrm{O} 18$, O21, O22, O25, O75 and O83 serogroups are preferentially associated with UPEC strains [5-13]. Some of the most important virulence genes of UPEC strains which are associated with severe UTIs are P fimbriae (pap), type 1 fimbriae, afimbrial adhesin I (afal), hemolysin (hly), cytotoxic necrotizing factor 1 ( $c n f 1$ ), aerobactin (aer), S fimbriae $(s f a)$, adhesins and fimbriae [14, 15]; however, other virulence genes such as kpsMT, ompT, usp, iroN, iha, set 1, ast A, group II capsule synthesis; $s f a / f o c, \mathrm{~S}$ and F1C fimbriae; iutA, traT, serum resistance; and fim $H$, are known to be involved in pathogenicity of this organism [16-18]. These Virulence factors help the organisms to colonize host surfaces, avoid and/or subvert host defense mechanisms, injure and/or invade host cells and tissues, and incite a noxious inflammatory response, thereby leading to clinical disease [19]. Uropathogenic E. coli strains more frequently produce Pap and Prs fimbrial adhesins. P fimbriae are important for colonization and persistence of $E$. coli in the colon and possibly facilitate spread to the urinary tract $[20,21]$. The ability to constitute biofilm plays an important role in virulence of the bacteria, in addition to it; various genes encode urinary virulence factors.

In addition, several studies showed that antibiotic resistance in UPEC is increasing nowadays [22, 23]. Several studies have reported increasing trends in resistance against trimethoprim-sulfamethoxazole (TMP -SMZ) $[24,25]$ fluoroquinolones and other antibiotics, including ciprofloxacin $[26,27]$. To reduce the rate of morbidity, an early treatment of UTIs is mandatory, which relays on empirical therapies. However, to initiate an effective empirical treatment, several factors must be taken into consideration, including geographical location, age and sex of the patient, and local antimicrobial resistance profiles of the pathogens.

The identification of bacterial resistance genes seems to be essential to reduce the treatment costs. Using phylogenetic grouping as defined by multilocus enzyme electrophoresis and muliplex polymerase chain reaction (PCR) assays, Johnson et al. reported detailed analyses about phylogenetic background and virulence attributes of uropathogenic E. coli strains isolated from urosepsis and cystitis [28]. To our knowledge, there is scarcity of data showing the common uropathogenic E. coli serogroups in causing urinary tract infections, antibiotic resistance pattern of strains and frequency distribution of types of virulence genes in isolations having the ability to constitute biofilm in Iran. Therefore, in this study, we determined to track the common uropathogenic E. coli serogroups, antimicrobial susceptibility patterns and the virulence gene distribution of UPEC strains having the ability to constitute biofilm isolated from patients with UTIs in Iran.

\section{Methods}

Bacterial strains and detection of uropathogenic $E$. coli serogroups and virulence genes

In the present study, a total of $130 \mathrm{E}$. coli strains isolates were isolated and collected from urine specimens of patients with UTI who that had been referred to the medical laboratory. The strains were isolated from pure cultures and identified and also confirmed biochemically and using molecular techniques in the laboratory.

The colonies were confirmed using Polymerase Chain Reaction (PCR) based on the detection of 16S rRNA gene region of E. coli described by Sabat et al., (2000) [29]. In addition, all isolates were serogrouped using PCR assays. Table 1 showed the primers used for detection of UPEC serogroups and the PCR conditions [30]. The oligonucleotide sequences and Multiplex Polymerase Chain Reaction conditions of the specific primers were used to amplify the pap, fimH, sfa and afa genes producing biofilm in uropathogenic $E$. coli are shown in Table 2 [30]. The amplified products were visualized by ethidium bromide staining after gel electrophoresis of $10 \mu \mathrm{L}$ of the final reaction mixture in $1.5 \%$ agarose.

\section{Detection of biofilm formation and antimicrobial susceptibility testing}

All E. coli strains were included in the study and were analyzed for the production of biofilm and antimicrobial susceptibility pattern. Biofilm production in bacterial cultures was determined by Congo-red Agar method (CRA) as described previously by Solati et al. [31]. Congo-red was prepared as the aqueous solution, autoclaved, and then added when the agar cooled to $55{ }^{\circ} \mathrm{C}$. Plates were inoculated and incubated for 24 hours at $37{ }^{\circ} \mathrm{C}$. The positive isolate was indicated by black and dry crystalline colonies. Weak biofilm producers usually remained pink with the darkness at the center of colonies. Intermediate results were exhibited by the darkness of the colonies with the absence of a dry crystalline colonies.

Antimicrobial susceptibility testing was done by the Kirby-Bauer disc diffusion method using Mueller-Hinton agar (HiMedia Laboratories, Mumbai, India) according to the Clinical Laboratory Standards Institute (CLSI) guidelines [32] as has been previously described [30].

The antimicrobial agents tested and their corresponding concentrations were ampicillin (AM), tetracycline (TE), nalidixic acid (NA), co-trimoxazole (SXT), cephalothin $(\mathrm{CF})$, ciprofloxacin $(\mathrm{CP})$, norfloxacin (NOR), ceftriaxone (CRO), amikacin (AN), imipenem (IMP), gentamicin (GM) and nitrofurantoin (FM). 
Table 1 The oligonucleotide primers and the Multiplex PCR programs used for amplification of O-serogroups genes of E. coli isolates

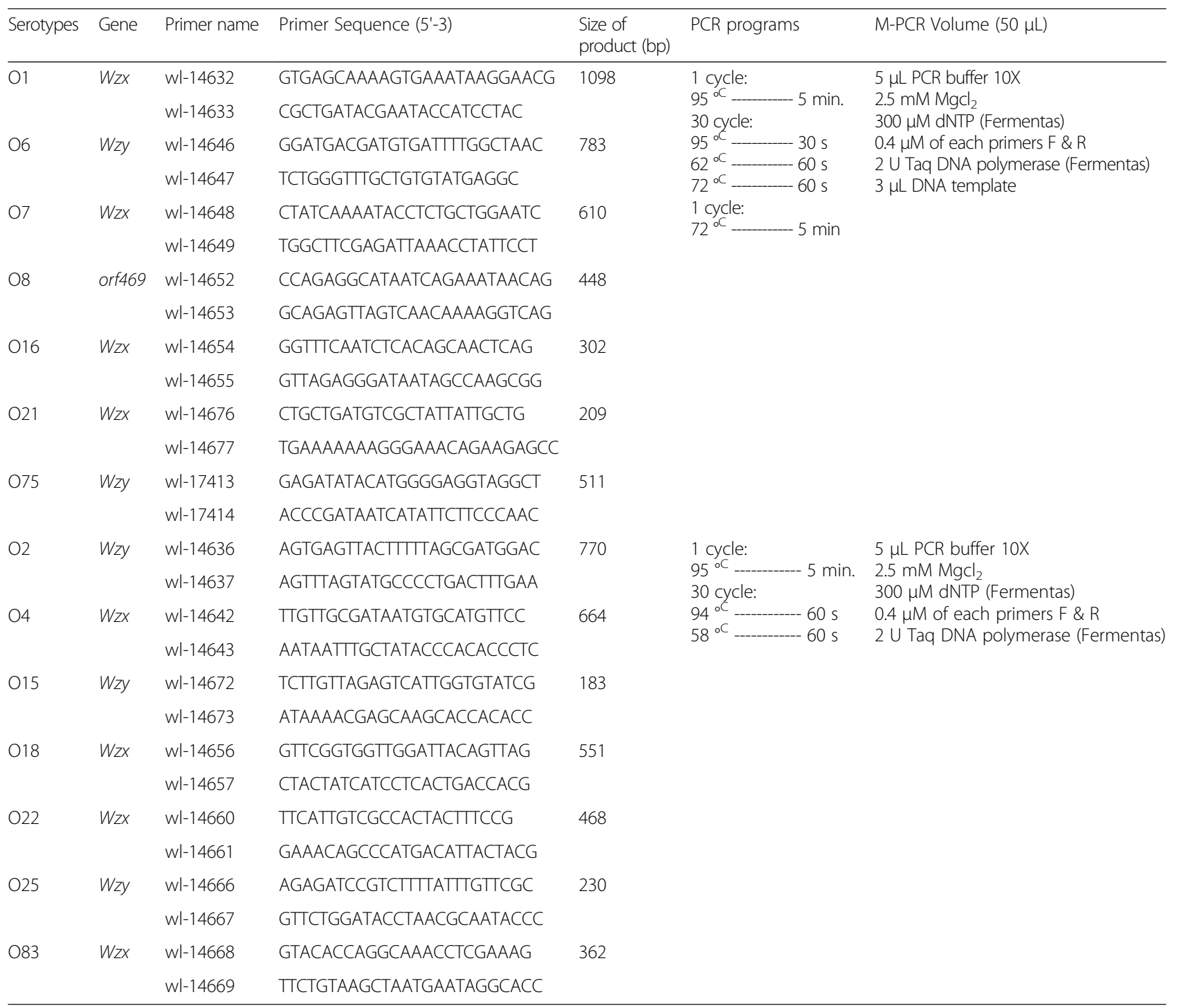

Table 2 The oligonucleotide primers and the Multiplex PCR programs used for amplification of virulence genes of E. coli isolates

\begin{tabular}{|c|c|c|c|c|c|}
\hline Gene & Primer name & Primer sequence $\left(5^{\prime}-3\right)$ & Size of product (bp) & PCR program & M-PCR volume $(50 \mu \mathrm{L})$ \\
\hline pap & $\begin{array}{l}\text { pap3 } \\
\text { pap4 }\end{array}$ & $\begin{array}{l}\text { GCAACAGCAACGCTGGTTGCATCAT } \\
\text { AGAGAGAGCCACTCTTATACGGACA }\end{array}$ & 336 & \multirow{3}{*}{ 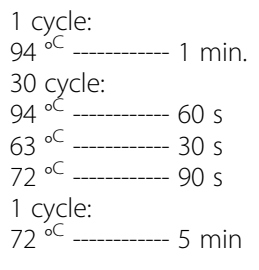 } & \multirow{3}{*}{$\begin{array}{l}5 \mu \mathrm{L} \text { PCR buffer 10X } \\
1.25 \mathrm{mM} \text { Mgcl } \\
150 \mu \mathrm{M} \text { dNTP (Fermentas) } \\
1 \mu \mathrm{M} \text { of each primers } \mathrm{F} \& \mathrm{R} \\
1.2 \mathrm{U} \text { Taq DNA polymerase (Fermentas) } \\
3 \mu \mathrm{L} \text { DNA template }\end{array}$} \\
\hline Sfa & $\begin{array}{l}\text { sfal } \\
\text { sfa2 }\end{array}$ & $\begin{array}{l}\text { CTCCGGAGAACTGGGTGCATCTTAC } \\
\text { CGGAGGAGTAATTACAAACCTGGCA }\end{array}$ & 410 & & \\
\hline Afa & $\begin{array}{l}\text { afal } \\
\text { afa2 }\end{array}$ & $\begin{array}{l}\text { GCTGGGCAGCAAACTGATAACTCTC } \\
\text { CATCAAGCTGTTTGTTCGTCCGCCG }\end{array}$ & 750 & & \\
\hline $\mathrm{fimH}$ & $\begin{array}{l}\text { FimH1 } \\
\text { FimH2 }\end{array}$ & $\begin{array}{l}\text { GAGAAGAGGTTTGATTTAACTTATTG } \\
\text { AGAGCCGCTGTAGAACTGAGG }\end{array}$ & 559 & 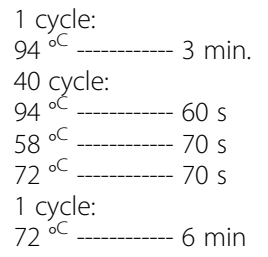 & $\begin{array}{l}5 \mu \mathrm{L} \text { PCR buffer 10X } \\
2 \mathrm{mM} \text { Mgcl } \\
200 \mu \mathrm{M} \text { dNTP (Fermentas) } \\
0.4 \mu \mathrm{M} \text { of each primers } \mathrm{F} \& \mathrm{R} \\
1 \cup \text { Taq DNA polymerase (Fermentas) } \\
3 \mu \mathrm{L} \text { DNA template }\end{array}$ \\
\hline
\end{tabular}




\section{Statistical analysis}

SPSS version 17.0 statistical software package was used for statistical analysis. Chi-square test was applied. $P$-value $<0.05$ was considered statistically significant

\section{Results}

Among 130 E.coli isolates, 80 (61.53 \%) were able to make biofilm. Among $80 \mathrm{E}$. coli strains subjected to biofilm production, 15 (18.75\%) strains showed highly positive with very black colonies color in Congo Red Agar (CRA), 20 strains $(25 \%)$ showed moderate positive with black colonies color in CRA, 45 strains (56.25\%) showed weakly positive with grey colonies color in CRA. Dry crystalline and black colonies at the Congo-red Agar culture, were considered as strong biofilm producers; isolates did not show dry crystalline black colonies were identified as moderately biofilm producers and non-biofilm producers showed pink or yellow colonies.

Antibiotic susceptibility pattern was studied for all $E$. coli isolates. The multi-drug resistant pattern of the biofilm producing and non producing UPEC $E$. coli is shown in Table 3. All the biofilm forming strains showed maximum resistance to ampicillin (87.5\%), followed by tetracycline (75\%), nalidixic Acid (72.5 \%) and co-trimoxazole (71.25\%). Both biofilm producer and non- biofilm producer were highly resistant to ampicillin, followed by tetracycline and nalidixic acid. $93.75 \%$ and $98 \%$ sensitive was noticed for biofilm and non-biofilm producer against nitrofurantoin, respectively.

Our results revealed high distribution of UPEC serogroups isolated from patients with urinary tract infection. Totally, O25 (26.66 \%), O15 (20.0\%) and O16 (13.33\%) had the highest biofilm producing serogroups while $\mathrm{O} 2, \mathrm{O} 4, \mathrm{O} 6, \mathrm{O} 8, \mathrm{O} 21$ and $\mathrm{O} 22$ had the lowest biofilm producing serogroups which showed (6.66 \%) among Uropathogenic E. coli isolates detected (Table 4).

In the present study the prevalence of fimH, pap, sfa and afa genes in Uropathogenic E. coli was determined and the result showed that among high biofilm producer Uropathogenic E. coli isolates fimH gene was the highest prevalence and afa gene was the lowest prevalence virulence gene (Table 5). Biofilm production was significantly associated with $f i m H$, pap, afa and sfa virulence genes $(P<0.05)$.

\section{Discussion}

Urinary tract infections are among the most common bacterial diseases worldwide which involve (infects) about 250 million people in developing countries annually [33, 34]. Uropathogenic E. coli alone account for $70-90 \%$ of the UTI infections $[35,36]$ and their susceptibility patterns against different antibiotics vary in different geographical regions, eventually leading to empirical therapy which is based on the local susceptibility profiles. Bacterial biofilm are often associated with long-term persistence of organism in various environments. Bacteria in biofilm display dramatically increased resistance to antibiotics [37].

Among $80 \mathrm{E}$. coli isolates subjected to biofilm production, $15(18.75 \%)$ isolates showed highly positive, 20 isolates (25\%) showed moderate positive, 45 isolates (56.25\%) showed weakly positive in Congo Red Agar method (CRA). Antibiotic susceptibility pattern was studied for all E. coli isolates.

The biofilm forming isolates showed maximum resistance to Ampicillin (87.5\%), followed by Tetracycline (75 \%), Nalidixic Acid (72.5\%) and Co-Trimoxazole (71.25\%). Both biofilm producer and non- biofilm producer were highly resistant to Ampicillin, followed by Tetracycline and Nalidixic Acid. $93.75 \%$ and $98 \%$

Table 3 Antibiotic resistance pattern of the biofilm producing and non producing Uropathogenic E. coli

\begin{tabular}{llllr}
\hline Antibiotic & \multicolumn{2}{l}{ Biofilm producer $(N=80)$} & & \multicolumn{2}{l}{ Non biofilm producer $(N=50)$} \\
\cline { 2 - 3 } & Resistance & Sensitive & $40(80 \%)$ & Sensitive \\
\hline Ampicillin (AM) & $70(87.5 \%)$ & $10(12.5 \%)$ & $35(70 \%)$ & $10(20 \%)$ \\
Tetracycline (TE) & $60(75 \%)$ & $20(25 \%)$ & $34(68 \%)$ & $15(30 \%)$ \\
Nalidixic Acid (NA) & $58(72.5 \%)$ & $22(27.5 \%)$ & $33(66 \%)$ & $16(32 \%)$ \\
Co-Trimoxazole (SXT) & $57(71.25 \%)$ & $23(28.75 \%)$ & $28(56 \%)$ & $22(44 \%)$ \\
Cephalothin (CF) & $45(56.25 \%)$ & $35(43.75 \%)$ & $27(54 \%)$ & $23(46 \%)$ \\
Ciprofloxacin (CP) & $45(56.25 \%)$ & $35(43.75 \%)$ & $26(52 \%)$ & $24(48 \%)$ \\
Norfloxacin (NOR) & $43(53.75 \%)$ & $37(46.25 \%)$ & $18(36 \%)$ & $30(60 \%)$ \\
Ceftriaxone (CRO) & $33(41.25 \%)$ & $47(58.75 \%)$ & $15(30 \%)$ & $32(64 \%)$ \\
Amikacin (AN) & $31(38.75 \%)$ & $49(61.25 \%)$ & $9(18 \%)$ & $35(70 \%)$ \\
Imipenem (IMP) & $25(31.25 \%)$ & $55(68.75 \%)$ & $1(2 \%)$ & $41(82 \%)$ \\
Gentamicin (GM) & $15(18.75 \%)$ & $65(81.25 \%)$ & $75(93.75 \%)$ & $49(98 \%)$ \\
Nitrofurantoin (FM) & $5(6.25 \%)$ & &
\end{tabular}


Table 4 Prevalence of serogroups Uropathogenic E. coli

\begin{tabular}{|c|c|c|c|c|c|c|c|c|c|c|c|c|c|c|}
\hline \multirow{2}{*}{$\begin{array}{l}\text { Number of positive } \\
\text { samples }\end{array}$} & \multicolumn{14}{|c|}{ Prevalence of serogroups (\%) } \\
\hline & 01 & $\mathrm{O} 2$ & $\mathrm{O} 4$ & O6 & $\mathrm{O} 7$ & O8 & 015 & 016 & 018 & $\mathrm{O} 21$ & $\mathrm{O} 22$ & $\mathrm{O} 25$ & $\mathrm{O} 75$ & O83 \\
\hline $\begin{array}{l}\text { High Biofilm Production } \\
\text { E. coli }(N=15)\end{array}$ & - & $1(6.66 \%)$ & $1(6.66 \%)$ & $1(6.66 \%)$ & - & $1(6.66 \%)$ & $3(20 \%)$ & $2(13.33 \%)$ & - & $1(6.66 \%)$ & $1(6.66 \%)$ & $4(26.66 \%)$ & - & - \\
\hline $\begin{array}{l}\text { Moderate Biofilm } \\
\text { Production E. coli }(N=20)\end{array}$ & $1(5 \%)$ & $1(5 \%)$ & $1(5 \%)$ & $1(5 \%)$ & $1(5 \%)$ & $1(5 \%)$ & $3(15 \%)$ & $2(10 \%)$ & $1(5 \%)$ & $1(5 \%)$ & $1(5 \%)$ & $5(25 \%)$ & 1 & - \\
\hline $\begin{array}{l}\text { Weak Biofilm Production } \\
\text { E. coli }(N=45)\end{array}$ & $1(2.22 \%)$ & 1 (2.22 \%) & $2(4.44 \%)$ & $6(13.33 \%)$ & 1 (2.22 \%) & 1 (2.22 \%) & $10(22.22 \%)$ & $5(11.11 \%)$ & $1(2.22 \%)$ & $2(4.44 \%)$ & $1(2.2 \%)$ & $13(28.88 \%)$ & $1(2.22 \%)$ & - \\
\hline No biofilm E. coli $(N=50)$ & $1(2 \%)$ & $1(2 \%)$ & $3(6 \%)$ & $8(16 \%)$ & $2(4 \%)$ & $1(2 \%)$ & 11 (22 \%) & $1(2 \%)$ & $1(2 \%)$ & $4(8 \%)$ & $1(2 \%)$ & $14(28 \%)$ & $1(2 \%)$ & $1(2 \%)$ \\
\hline
\end{tabular}


Table 5 Prevalence of fimH, pap, sfa and afa genes in Uropathogenic E. coli

\begin{tabular}{llllll}
\hline Virulence & UPEC E. coli & & & \\
\cline { 2 - 6 } gene & High biofilm producer 15 & Moderate biofilm producer 20 & Weak biofilm producer 45 & Non biofilm producer 50 & $P$ value \\
\hline fimH & $14(93.33 \%)$ & $18(90 \%)$ & $35(77.77 \%)$ & $30(60 \%)$ & 0.031 \\
pap & $13(86.66 \%)$ & $16(80 \%)$ & $30(71.42 \%)$ & $28(56 \%)$ & 0.001 \\
sfa & $13(86.66 \%)$ & $10(50 \%)$ & $20(44.44 \%)$ & $20(40 \%)$ & 0.033 \\
afa & $10(66.66 \%)$ & $7(35 \%)$ & $15(33.33 \%)$ & $10(20 \%)$ & 0.035 \\
\hline
\end{tabular}

sensitivity was noticed for biofilm and non-biofilm producer against Nitrofurantoin, respectively. The findings of the current investigations are in agreement with the reports of Reisner et al. [38] ; Ong et al. [39]; Ulett et al. [40] and Ulett et al. [41] in which a greater variation was observed against the uropathogenic $E$. coli forming biofilms under different conditions. Another finding of this study is that strong biofilm producers were less susceptible to antimicrobial agents than the non-biofilm producer. This result may agree with the previous studies showing that the sessile bacterial cells seems to exhibit higher resistance than the planktonic cells [42-48], so the findings of the current investigation indicated that resistance mechanisms are associated with the formation of biofilm among uropathogenic E. coli.

Similarly, the increasing prevalence of multi-drug resistance (MDR) has been reported by other workers showed, of the 100 (60.2 \%) E. coli strains, 72 strains displayed a biofilm positive phenotype under the optimized conditions in the Congo Red agar medium and the strains were classified as highly positive (17, $23.6 \%)$, moderate positive $(19,26.3 \%)$ and weakly positive (36, $50.0 \%$ ). The rates of antibiotic resistance of biofilm producing E. coli were found to be $100 \%$ for chloramphenicol and amoxyclav (amoxicillin and clavulanic acid), $86 \%$ for gentamicin and cefotaxime, $84 \%$ for ceftazidime, $83 \%$ for cotrimoxazole and piperacillin/tazobactam, $75 \%$ for tetracycline and $70 \%$ for amikacin [49]. This could be due to dissemination of MDR strains in hospital settings and the different combination of antibiotics resulted in varying degree of resistance among the biofilm producing uropathogenic $E$. coli.

In addition, $56.25 \%$ of biofilm-producing UPEC isolates showed resistance to Cephalothin. Similar findings had been previously observed in South East Asian region [50-52]. Reported resistance rate against these drugs was comparatively lower in previous study in Iran (19.6 \%) [53] and in Bangladesh, it was $32 \%$ [54]. However, observed higher percentages of resistances against Cephalothin drugs indicated that they could render their efficacies as therapeutic agents, particularly in Iranian population. In general, our results suggest that transformation of UTIassociated $E$. coli with plasmids carrying different antibiotic resistance gene had a significant impact on biofilm formation and that these effects were both strain dependent and varied between different antibiotics.
Our results revealed high distribution of UPEC serogroups isolated from patients with urinary tract infection. Totally, O25 (26.66 \%), O15 (20.0\%) and O16 (13.33\%) had the highest biofilm producing serogroups while $\mathrm{O} 2, \mathrm{O} 4, \mathrm{O} 6, \mathrm{O} 8, \mathrm{O} 21$ and $\mathrm{O} 22$ had the lowest biofilm producing serogroups which showed $(6.66 \%)$ among Uropathogenic E. coli isolates detected (Table 4). In the present study the prevalence of $f i m H$, pap, sfa and $a f a$ genes in Uropathogenic E. coli was determined and the result showed that among High biofilm producer Uropathogenic E. coli isolates fimH gene was the highest prevalence and afa gene was the lowest prevalence virulence gene (Table 5). Biofilm production was significantly associated with $\mathrm{fimH}$, pap, $a f a$ and $s f a$ virulence genes $(P<0.05)$. Manuela et al. reported that Biofilm production was significantly associated with fluoroquinolone resistance at all incubation time points and was independent of the media used $(P<0.05)$. Biofilm production was not associated with $c n f 1, h l y$, pap and sfa genes $(P>0.05)$, but was significantly associated with $a f a$ aer and the $\beta$-lactamase genes $(P<0.05)[55]$.

\section{Conclusions}

Urinary tract infections are one of the common infections which are encountered in the clinical practice. This study reveals the prevalence and antimicrobial susceptibility pattern of biofilm and non-biofilm producing uropathogenic $E$. coli strains. Biofilm formation is closely related with the resistance of $E$. coli towards the antimicrobial drugs and also it increases the chronicity of urinary tract infection. In general, the current study demonstrated a high tendency among the clinical isolates of $E$. coli to form biofilm. The present study has also shown the production of various virulent factors and developing drug resistance in UPEC. Antibiotic resistance may provide a substantial advantage to the survival of the pathogen. The drug resistance among UPEC is on rise therefore the selection of appropriate antibiotics (after antibiotic susceptibility testing) is must for proper treatment of patients and to avoid emergence of drug resistance. Therefore, the knowledge of virulence factors of E. coli and their antibiotic susceptibility pattern will help in better understanding of the organism and in the treatment of UTI. 


\section{Abbreviations}

UPEC: Uropathogenic E. coli; UTIs: Urinary Tract Infections; E. coli: Escherichia coli; aer: Aerobactin; pap: P fimbriae; afa I: Type 1 fimbriae, afimbrial adhesin; hly: Hemolysin; cnf 1: Cytotoxic necrotizing factor 1; sfa: S fimbriae; PCR: Polymerase chain reaction; CRA: Congo red agar; CLSI: Clinical and Laboratory Standards Institute; MHA: Mueller Hinton agar; AM: Ampicillin; TE: Tetracycline; NA: Nalidixic acid; SXT: Co-trimoxazole; CF: Cephalothin CP: Ciprofloxacin; NOR: Norfloxacin; CRO: Ceftriaxone; AN: Amikacin; IMP: Imipenem; GM: Gentamicin; FM: Nitrofurantoin; SPSS: Statistical package for the social sciences.

\section{Competing interests}

The authors declare that they have no competing interests.

\section{Authors' contribution}

All authors had participated equally. All authors read and approved the final manuscript.

\section{Acknowledgements}

The authors would like to thank all who contributed directly or indirectly in conduction of this research.

\section{Author details}

'Department of Microbiology, Faculty of Basic Sciences, Shahrekord Branch, Islamic Azad University, Shahrekord, Iran. Faculty of Basic Sciences, Shahrekord Branch, Islamic Azad University, Shahrekord, Iran. ${ }^{3}$ Department of Microbiology, Damghan Branch, Islamic Azad University, Damghan, Iran. ${ }^{4}$ Cellular and Molecular Research Center, Sabzevar University of Medical Sciences, Sabzevar, Iran.

Received: 23 December 2015 Accepted: 21 March 2016 Published online: 01 April 2016

\section{References}

1. Schaeffer AJ. Infections of the urinary tract. In: Walsh PC, Retik $A B$, Vaughan Jr AJ, et al., editors. Campbell's Urology, vol. 1. 8th ed. Philadelphia: WB Saunders; 2002. p. 515-602.

2. Seema M, Madhu S, Uma C. Biofilm and multidrug resistance in uropathogenic Escherichia coli. Pathog Glob Health. 2015;109(1):26-9.

3. Spoering AM, Lewis K. Biofilm and planktonic cells of Pseudomonas aeruginosa have similar resistance to killing by antimicrobials. J Bacteriol. 2001;183:6746-51.

4. Liu Y, Yan X, DebRoy C, Fratamico PM, Needleman DS, Li RW, Wang W, Losada L, Brinkac L, Radune D, Toro M, Hegde N, Meng J. Escherichia coli OAntigen Gene Clusters of Serogroups O62, O68, 0131, 0140, 0142, and O163: DNA Sequences and Similarity between 062 and O68, and PCR-Based Serogrouping. Biosensors (Basel). 2015:5(1):51-68. doi:10.3390/bios5010051.

5. Abe CM, Salvador FA, Falsetti IN, Vieira MA, Blanco J, Blanco JE, et al. Uropathogenic Escherichia coli (UPEC) strains may carry virulence properties of diarrhoeagenic E. coli. FEMS Immunol Med Microbiol. 2008;52(3):397-406.

6. Ananias M, Yano T. Serogroups and virulence genotypes of Escherichia coli isolated from patients with sepsis. Braz J Med Biol Res. 2008;41(10):877-83.

7. Bidet P, Mahjoub-Messai F, Blanco J, Blanco J, Dehem M, Aujard Y, Bingen E, Bonacorsi S. Combined multilocus sequence typing and $O$ serogrouping distinguishes Escherichia coli subtypes associated with infant urosepsis and/or meningitis. J Infect Dis. 2007;196(2):297-303.

8. Blanco M, Blanco JE, Alonso MP, Blanco J. Virulence factors and O groups of Escherichia coli isolates from patients with acute pyelonephritis, cystitis and asymptomatic bacteriuria. Eur J Epidemiol. 1996:12(2):191-8.

9. Johnson JR, Orskov I, Orskov F, Goullet P, Picard B, Moseley SL, Roberts PL, Stamm WE. O, K, and $\mathrm{H}$ antigens predict virulence factors, carboxylesterase B pattern, antimicrobial resistance, and host compromise among Escherichia coli strains causing urosepsis. J Infect Dis. 1994;169(1):119-26.

10. Lloyd AL, Rasko DA, Mobley HL. Defining genomic islands and uropathogen-specific genes in uropathogenic Escherichia coli. J Bacteriol. 2007:189(9):3532-46.

11. Orskov I, Orskov F, Birch-Andersen A, Kanamori M, Svanborg-Edén C. O., K, H and fimbrial antigens in Escherichia coli serotypes associated with pyelonephritis and cystitis. Scand J Infect Dis Suppl. 1982;33:18-25.
12. Yamamoto S. Molecular epidemiology of uropathogenic Escherichia coli. J Infect Chemother. 2007;13(2):68-73.

13. Hemmatinezhad B, Khamesipour F, Mohammadi M, Safarpoor Dehkordi F, Mashak Z. Microbiological Investigation of O-Serogroups, Virulence Factors and Antimicrobial Resistance Properties of Shiga Toxin-Producing Escherichia Coli Isolated from Ostrich, Turkey and Quail Meats. J Food Saf. 2015;35:491-500. doi:10.1111/jfs.12199.

14. Donnenberg M, Welch RA. Virulence determinants of uropathogenic Escherichia coli. In: Mobely HLT, Warren JW, editors. Urinary Tract Infections. Molecular Pathogenesis and Clinical Management. Washington, DC: American Society for Microbiology; 1995. p. 135-74.

15. Johnson JR. Virulence factors in Escherichia coli urinary tract infection. Clin Microbiol Rev. 1991:4(1):80-128

16. Soto SM, Guiral E, Bosch J, Vila J. Prevalence of the set-1B and astA genes encoding enterotoxins in uropathogenic Escherichia coli clinical isolates. Microb Pathog. 2009;47(6):305-7.

17. Bauer RJ, Zhang L, Foxman B, Siitonen A, Jantunen ME, Saxen H, Marrs CF. Molecular epidemiology of 3 putative virulence genes for Escherichia coli urinary tract infection-usp, iha, and iroN (E. coli). J Infect Dis. 2002;185(10):1521-4.

18. Johnson JR, Russo TA, Tarr PI, Carlino U, Bilge SS, Vary Jr JC, Stell AL. Molecular epidemiological and phylogenetic associations of two novel putative virulence genes, iha and iroN (E. coli), among Escherichia coli isolates from patients with urosepsis. Infect Immun. 2000;68(5):3040-7.

19. Johnson JR, O'Bryan TT, Kuskowski M, Maslow JN. Ongoing horizontal and vertical transmission of virulence genes and papA alleles among Escherichia coli blood isolates from patients with diverse-source bacteremia. Infect Immun. 2001;69:5363-74.

20. Herias MV, Midvedt T, Hanson LA, Wold AE. Role of Escherichia coli P fimbriae in intestinal colonization in gnotobiotic rats. Infect Immun. 1995;63:4781-9.

21. Wold EA, Caugant DA, Lidin-Janson G, De Man P, Svanborg C. Resident colonic Escherichia coli strains frequently display uropathogenic characteristics. J Infect Dis. 1992:165:46-52.

22. Johnson JR, Kuskowski MA, O'bryan TT, Colodner R, Raz R. Virulence genotype and phylogenetic origin in relation to antibiotic resistance profile among Escherichia coli urine sample isolates from Israeli women with acute uncomplicated cystitis. Antimicrob Agents Chemother. 2005;49(1):26-31.

23. Sahm DF, Thornsberry C, Mayfield DC, Jones ME, Karlowsky JA. Multidrugresistant urinary tract isolates of Escherichia coli: prevalence and patient demographics in the United States in 2000. Antimicrob Agents Chemother. 2001:45:1402-06.

24. Nys S, Van Merode T, Bartelds Al, Stobberingha EE. Antibiotic treatment and resistance of unselected uropathogens in the elderly. Int J Antimicrob Agents. 2006;27:236-41

25. Karlowsky JA, Hoban DJ, Decorby MR, Laing NM, Zhanel GG. Fluoroquinolone-resistant urinary isolates of Escherichia coli from outpatients are frequently multidrug resistant: results from the North American Urinary Tract Infection Collaborative Alliance-Quinolone Resistance study. Antimicrob Agents Chemother. 2006;50:2251-54

26. Park CH, Robicsek A, Jacoby GA, Sahm DF, Hooper DC. Prevalence in the United States of aac (6')-lb-cr encoding a ciprofloxacin-modifying enzyme. Antimicrob Agents Chemother. 2006:50:3953-55.

27. Johnson JR, Johnston B, Kuskowski MA, Colodner R, Raz R. Spontaneous conversion to quinolone and fluoroquinolone resistance among wildtype Escherichia coli isolates in relation to phylogenetic background and virulence genotype. Antimicrob Agents Chemother. 2005;49(11):4739-44

28. Johnson JR, O'Bryan TT, Delavari P, Kuskowski M, Stapleton A, Carlino U, Russo TA. Clonal relationships and extended virulence genotypes among Escherichia coli isolates from women with a first or recurrent episode of cystitis. J Infect Dis. 2001;183:1508-17.

29. Sabat G, Rose P, Hickey WJ, Harkin JM. Selective and sensitive method for PCR amplification of Escherichia coli 16S rRNA genes in soil. Appl Environ Microbiol. 2000;66:844-9.

30. Momtaz H, Karimian A, Madani M, Safarpoor Dehkordi F, Ranjbar R, Sarshar M, Soud N. Urophathogenic Escherichia coli in Iran serogroup distributions, virulence factors and antimicrobial resistance properties. Ann Clin Microbiol Antimicrob. 2013;12:1-8

31. Solati SM, Tajbakhsh E, Khamesipour F, Gugnani HC. Prevalence of virulence genes of biofilm producing strains of Staphylococcus epidermidis isolated from clinical samples in Iran. AMB Express. 2015:5:47. doi:10.1186/ s13568-015-0134-3. 
32. Clinical and Laboratory Standards Institute (CLSI). Performance Standards for Antimicrobial Disk Susceptibility Tests, Approved standard-Ninth Edition (M2-A9). Wayne, PA: Clinical and Laboratory Standards Institute; 2006.

33. Ronald AR, Nicolle LE, Stamm E, Krieger J, Warren J, Schaeffer A, Naber KG, Hooton TM, Johnson J, Chambers S, Andriole V. Urinary tract infection in adults: Research priorities and strategies. Int J Antimicrob Agents. 2001;17:343-48

34. Tajbakhsh E, Tajbakhsh S, Khamesipour F. Isolation and Molecular Detection of Gram Negative Bacteria Causing Urinary Tract Infection in Patients Referred to Shahrekord Hospitals. Iran Iran Red Crescent Med J. 2015;17(5), e24779. doi:10.5812/ircmj.17(5)2015.24779.

35. Ulleryd P. Febrile urinary tract infection in men. Int J Antimicrob Agents. 2003:22:89-93.

36. Gupta K, Hooton TM, Stamm WE. Increasing antimicrobial resistance and the management of uncomplicated community-acquired urinary tract infections. Ann Intern Med. 2001;135:41-50.

37. Graham JC, Galloway A. ACP best practice No 167: The laboratory diagnosis of urinary tract infection. J Clin Pathol. 2001;54:911-9.

38. Reisner A, Krogfelt KA, Klein BM, Zechner EL, Molin S. In vivo biofilm formation of commensal and pathogenic Escherichia coli strains: impact of environmental and genetic factors. J Bacteriol. 2006;188:3572-81.

39. Ong CLY, Ulett GC, Mabbett AN, Beaston SA, Webb Rl, Monaghan W, Nimmo GR, Looke DF,McEwan AG, Schembri MA. Identification of type 3 fimbriae in uropathogenic Escherichia coli reveals a role in biofilm formation. J Bacteriol. 2008;190:1054-63.

40. Ulett GC, Valle J, Beloin C, Sherlock O, Ghigo JM, Schembri MA. Functional analysis of antigen 43 in uropathogenic Escherichia coli reveals a role in long term persistence in the urinary tract. Infect Immun. 2007;75:3233-44.

41. Ulett GC, Mabbett AN, Fung KC, Webb Rl, Schembri MA. The role of F9 fimbriae of uropathogenic Escherichia coli in biofilm formation. Microbiology. 2007;151:2321-31.

42. Jefferson KK. What drives bacteria to produce a biofilm? FEMS Microbiol Lett. 2004;236:163-73.

43. Kumar DT, Pankaja SS, Rao HK, Kate V. Evaluation of Helicobacter pylori infection and other risk factors in patients with benign peptic ulcer disease. Asian Pac J Trop Dis. 2011;1(1):50-1.

44. Owolabi RS, Daniel O, Araoye MO, Osagbemi GK, Odeigah L, Ogundiran A. Self-reported reasons for seeking HIV testing by people living with HIV/AIDS(PLWHA) in a tertiary hospital in Nigeria. Asian Pac J Trop Dis. 2011;1(1):59-62.

45. Wilma DSC, Kavya N, Kulkarni S. Evaluation of insulin sensitivity status in polycystic ovarian syndrome. Asian Pac J Trop Dis. 2011;1(1):67-70.

46. Karki S, Kumar K. Study on the possible use of Vi polysaccharide typhoid fever vaccine to control endemic typhoid fever in Nepal. Asian Pac J Trop Dis. 2011;1(1):76-9.

47. Mirnejad R, Jeddi F, Kiani J, Khoobdel M. Etiology of spontaneous bacterial peritonitis and determination of their antibiotic susceptibility patterns in Iran. Asian Pac J Trop Dis. 2011;1(2):116-8.

48. Sauer K, Rickard AH, Davies DG. Biofilm and biocomplexity. Microbe. 2007;7:347-53.

49. Ponnusamy $P$, Natarajan $V$, Sevanan M. In vitro biofilm formation by uropathogenic Escherichia coli and their antimicrobial susceptibility pattern. Asian Pac J Trop Med. 2012;210-213.

50. Tanvir R, Hafeez R, Hasnain S. Prevalence of Multiple Drug Resistant E. Coli in patients of Urinary tract infection registering at a Diagnostic Laboratory in Lahore. Pakistan J Zool. 2012;44:707-12.

51. Sotto A, Crinne DM, Parcale B, Peray F, Gouby A, Jacques D. Risk factors for antibiotics resistant $E$. Coli isolated from hospitalized patients with U.T.I: A prospective study. J Clin Microbiol. 2001;39:438-44.

52. Akram M, Shahid M, Khan AU. Etiology and antibiotic resistance patterns of community-acquired urinary tract infections in JNMC Hospital Aligarh. India Ann Clin Microbiol Antimicrob. 2007;6:4.

53. Farshad S, Ranjbar R, Japoni A, Hosseini M, Anvarinejad M, Mohammadzadegan R. Microbial Susceptibility, Virulance Factor, and Plasmid profiles of Uropathogenic E. Coli Strains Isolated from Children in Jahrom Arch Iran Med. 2012;15:5.

54. Marhova M, Kostadinova S, Stoitsova S. Antimicrobial resistance profiles of urinary Escherichia coli isolates. Biotechnol Biotechnol. 2009;23(sup1):616-20. doi:10.1080/13102818.2009.10818500.

55. Manuela O, Filipa RD, Constança P. Biofilm and fluoroquinolone resistance of canine Escherichia coli uropathogenic isolates. BMC Res Notes. 2014;7:499.

\section{Submit your next manuscript to BioMed Central and we will help you at every step:}

- We accept pre-submission inquiries

- Our selector tool helps you to find the most relevant journal

- We provide round the clock customer support

- Convenient online submission

- Thorough peer review

- Inclusion in PubMed and all major indexing services

- Maximum visibility for your research

Submit your manuscript at www.biomedcentral.com/submit 